\title{
CONTAMINAÇÃO DE APARELHOS CELULARES DA EQUIPE DE ENFERMAGEM EM UNIDADE DE TERAPIA INTENSIVA DE UM HOSPITAL PÚBLICO DO NOROESTE PARANAENSE
}

\author{
Guilherme de Souza Cabral ${ }^{1}$ \\ Jhonatan Gabriel de Paula Lopes ${ }^{2}$ \\ Carlos Eduardo Benevento ${ }^{3}$ \\ Marielle Priscila de Paula Silva-Lalucci ${ }^{4}$
}

\begin{abstract}
CABRAL, G. de S.; LOPES, J. G. de P.; BENEVENTO, C. E.; SILVA-LALUCCI, M. P. de P. Contaminação de aparelhos celulares da equipe de enfermagem em unidade de terapia intensiva de um hospital público do noroeste paranaense. Arquivos de Ciências da Saúde da UNIPAR, Umuarama, v. 25, n. 2, p, 111-116, maio/ago. 2021.
\end{abstract}

RESUMO: O ambiente hospitalar é um dos locais com maiores chances de acontecer quadros de infecções, sendo um dos motivos a utilização irrestrita dos aparelhos celulares tanto por pacientes quanto por profissionais da saúde que não se preocupam com as boas práticas de higienização. O objetivo deste estudo foi determinar a prevalência de micro-organismos em aparelhos celulares da equipe de enfermagem da Unidade de Terapia Intensiva (UTI) de um hospital na região noroeste paranaense. Participaram da pesquisa 22 colaboradores da UTI, sendo colhidos swabs umedecidos em caldo Brain Heart Infusion (BHI) dos aparelhos celulares de cada um dos participantes e, posteriormente, as amostras foram incubadas e realizadas as análises microbiológicas. Além disso, aplicou-se um questionário para se conhecer sobre o manuseio do telefone celular por parte dos colaboradores. Na análise microbiológica, observou-se crescimento em todas as amostras de pelo menos um micro-organismo (100\% nos meios Ágar Sal Manitol e Ágar Sangue, e 27,3\% em Ágar MacConkey). Posteriormente, realizou-se comparação com as respostas do questionário e com o resultado da amostra, sendo que apenas $13,6 \%$ dos colaboradores relataram realizar sempre higienização dos aparelhos, porém também houve crescimento de micro-organismos nos aparelhos desses colaboradores. A partir dos dados obtidos, espera-se o envolvimento da Comissão de Controle de Infecção Hospitalar (CCIH) para desenvolver ações que reduzam a prevalência e a gravidade da contaminação no ambiente hospitalar.

PALAVRAS-CHAVE: Análise microbiológica. Infecção hospitalar. Telefone celular.

\section{CONTAMINATION OF CELL PHONES FROM THE NURSING TEAM IN AN INTENSIVE CARE UNIT IN A PUBLIC HOSPITAL IN THE NORTHWEST PARANAENSE}

\begin{abstract}
Hospital environments are one of the most likely places for the development of infections, with one of the reasons being the unrestricted use of cell phones by both patients and health professionals, with disregard to good hygiene practices. The purpose of this study is to determine the prevalence of microorganisms on cell phones of the nursing staff at the Intensive Care Unit (ICU) of a hospital in the northwestern region of Paraná. A total of twenty-four ICU employees participated in the research. Swabs were collected from the cell phones of each participant and were then moistened in Brain Heart Infusion (BHI) broth. Subsequently, the samples were incubated, and a microbiological analysis was carried out. In addition, a questionnaire was applied to learn out about the employee's handling of the cell phone. From the microbiological analysis, growth of at least one microorganism $(100 \%$ in the Agar Salt Mannitol and Blood Agar, and $27.3 \%$ in MacConkey Agar) could be observed in all samples. Subsequently, a comparison was made with the answers to the questionnaire and with the sample result, with only $13.6 \%$ of employees reporting that they always clean the devices. However, even the devices that were reported as being cleaned presented microorganisms. With the data obtained, the Hospital Infection Control Commission (HICC) is expected to be involved in order to develop actions to reduce prevalence, incidence, and the severity of contamination in hospital environments.
\end{abstract}

KEYWORDS: Cell Phone. Cross Infection. Microbiological Analysis.

Introdução

A partir do momento em que o homem passou a conviver em sociedade, a comunicação se tornou necessária para expressarem sentimentos, cultura ou alertar sobre algum perigo. Com o passar dos anos, as formas de comunicações evoluíram, estando em constante desenvolvimento de técnicas que facilitam a vida em sociedade (RAPPAPORT, 2009). Com a era da tecnologia e globalização no século XX houve a necessidade de criar um objeto que pudesse disseminar de forma mais rápida a comunicação. Assim sendo, inicialmente nos Estados Unidos e Japão, surgiram os aparelhos celulares que encurtaram o tempo e aproximaram as fronteiras na vida contemporânea e, dificilmente é impossível encontrar situações que o uso desses dispositivos não seja necessário (ARAÚJO et al., 2017).

Por ter-se tornado um acessório indispensável, os aparelhos celulares podem ser carregados para diversos locais, incluindo casa, trabalho, banheiros públicos e até mesmo emprestados para outras pessoas, se tornando um objeto propício para o crescimento de bactérias por estar em constante contato com a pele, saliva e calor (NUNES; SILIANO, 2016; REIS et al., 2015). Um dos principais motivos que levam a contaminação de aparelhos celulares por micro-organismos é a falta ou má higienização desses objetos. Devido aos afazeres do dia a dia as pessoas acabam

DOI: https://doi.org/10.25110/arqsaude.v25i2.2021.7995

${ }^{1}$ Acadêmico do Curso de Biomedicina, Centro Universitário de Maringá - UNICESUMAR. Rua José Granado Parra n 1048A, CEP 87047-550, Jardim Paulista, Maringá-Paraná, (44) 99869-8730. gcabral@alunos.unicesumar.edu.br

${ }^{2}$ Biomédico, Graduado em Biomedicina pelo Centro Universitário de Maringá - UNICESUMAR. Rua Adão Eloi Trojan n 265, CEP 87053-230, Jardim Ipanema, Maringá-Paraná, (44) 99709-0236.jhonatanglopes@gmail.com

${ }^{3}$ Coorientador, Mestre, Docente do Centro de Ciências da Saúde da UNICESUMAR, Maringá-PR. Avenida Pioneiro Antônio Ruiz Saldanha ${ }^{\circ}$ 1733, apto 1504, Residencial Portal do Japão. CEP 87065-303, Jardim das Estações, Maringá-Paraná, (44) 99952-1961. carlos.benevento@unicesumar.edu.br ${ }^{4}$ Orientadora, Mestre, Docente do Centro de Ciências da Saúde da UNICESUMAR, Maringá-PR. Rua Adolfo Alvez Ferreira n ${ }^{\circ}$ 52, apto 202, Residencial Corcovado. CEP 87005-250, Vila Marumby, Maringá-Paraná, (44) 99811-9499. marielle.silva@unicesumar.edu.br 
levando bactérias presentes na pele, por exemplo, para superfície desses aparelhos, que podem se disseminar em diversos ambientes, podendo causar infecções, dependendo da higienização e imunização dos acometidos (BALDO et al., 2016).

O ambiente hospitalar é um dos locais mais propícios para acontecer quadros de infecções, sendo a utilização irrestrita de celulares, tanto pelos pacientes quanto dos profissionais da saúde, um dos motivos com maior potencial de transmissão de doenças (ARAÚJO et al., 2017). As infecções relacionadas à assistência à saúde (IRAS), segundo a portaria $n^{\circ} 2616 / 98$ do Ministério da Saúde (BRASIL, 1998), são aquelas adquiridas após a admissão do paciente e que se manifestam durante a internação ou após a alta, e quando puderem ser relacionadas com internação ou procedimentos hospitalares. As IRAS são um quadro preocupante para pacientes hospitalizados, uma vez que sua debilidade facilita o desenvolvimento de novas patologias (SALOMÃO; PIGNATARI, 2004). Dentro dos hospitais existe uma Comissão de Controle de Infecção Hospitalar (CCIH) que em conjunto com outros profissionais dos setores e a direção do hospital tem como objetivo planejar, elaborar, implementar, manter e avaliar o Programa de Controle de Infecção Hospitalar - um conjunto de ações desenvolvidas com o objetivo de reduzir o máximo possível a incidência e a prevalência de infecções hospitalares (BARROS et al., 2016).

Existem várias medidas que ajudam a evitar IRAS, sendo a lavagem das mãos um dos métodos mais eficazes de prevenção, impedindo a transmissão de micro-organismos para outras pessoas. No ambiente hospitalar é importante que os visitantes sempre lavem as mãos antes e depois de visitarem os pacientes, além de usar, se necessário, alguns equipamentos de proteção individual como avental, máscara e luvas. A utilização de álcool em gel ou outros desinfetantes que contenham álcool também acabam sendo um agente que previne a disseminação de infecções; e as vacinas acabam se tornando também um meio eficiente para prevenção de doenças (TUNKEL, 2012).

O corpo humano é colonizado, de forma saudável, por um conjunto de micro-organismos que residem no mesmo, se distribuindo em diferentes órgãos e tecidos, que influenciam o sistema imunológico, a resistência aos patógenos e o aproveitamento dos alimentos, constituindo a microbiota humana. A microbiota traz diversos benefícios aos seres humanos, mantendo uma relação de simbiose, exercendo funções importantes e fundamentais para a saúde. Na microbiota humana os micro-organismos podem ser classificados em mutualistas (produzem nutrientes importantes que colaboram para o desenvolvimento do sistema imunológico), comensais (não apresentam benefícios ou malefícios ao hospedeiro) e oportunistas (podem causar doenças em indivíduos com o sistema imune comprometido) (CHAVASCO et al., 2017). Os profissionais da saúde costumam apresentar uma microbiota mais patogênica que outros indivíduos, sendo importante que exista uma higienização mais atenciosa nesse público, para que não ocorra a transmissão desses micro-organismos que são mais patógenos para outros indivíduos (CUSTÓDIO et al., 2009).

As bactérias podem ser classificadas principalmente em dois grupos de acordo com a estrutura da parede celular após a coloração de gram, sendo que as bactérias que apresentam parede celular composta por peptidoglicano durante o processo de descoloração com álcool etílico, retém o corante, chamadas de gram-positiva, enquanto que as bactérias com parede celular composta principalmente por ácidos graxos perdem o complexo iodo-pararosanilina, assumindo a cor do corante de fundo, chamadas de gramnegativas (BRASIL, 2001). Essa técnica é importante para análises clínicas, pois ajuda selecionar o melhor diagnóstico e tratamento. Através da extensão da pele encontramos a microbiota cutânea que tem predomínio de bactérias gram positivas principalmente do gênero Staphylococcus spp., Corynebacterium spp. e Propionibacterium spp. Além disso, a pele apresenta bactérias transitórias, que podem atuar como microbiota ou se tornarem patógenas, mas com uma higienização correta das mãos podem ser facilmente eliminadas (BALDO et al., 2016).

Dentro de uma Unidade de Terapia Intensiva (UTI), o uso dos aparelhos celulares de forma indevida acaba sendo um potencial veículo para transmissão de micro-organismos, através dos profissionais da área da saúde, como os enfermeiros, que manipulam diversos objetos e prestam cuidados aos pacientes em momentos intercalados, utilizando os celulares para facilitar estas atividades, principalmente na consulta de prontuários (STUCHI et al., 2013).

A UTI é descrita como um dos ambientes de maior contaminação em hospitais, sendo que estudos demonstram que $47 \%$ dos aparelhos celulares podem carregar bactérias potencialmente patogênicas, causando grandes preocupações, pois a contaminação contribui no aparecimento de novas patologias, levando a debilitação principalmente de pacientes (STUCHI et al., 2013).

De acordo com o estudo de Reis e colaboradores (2015) realizado em uma UTI, todas as amostras obtidas nos aparelhos celulares de funcionários obtiveram um crescimento de bactérias do gênero Staphylococcus, correspondendo $72 \%$ das amostras para coagulase negativo (SNC) e 28\% das amostras eram coagulase positiva (Staphylococcus aureus). As amostras positivas cresceram em meio de cultura Manitol e acidificaram o mesmo, assim constatando a presença de Staphylococcus aureus nos aparelhos avaliados. O número elevado de amostras com Staphylococcus pode ser notado porque são bactérias que fazem parte da microbiota da pele e de mucosas, podendo ocasionar diversos tipos de infecções, tendo um alto teor de crescimento microbiano, explicado pelo calor gerado dos aparelhos, tornando-se um ambiente propício de crescimento, além disso, são bactérias resistentes à secagem, podendo sobreviver por semanas (SOARES, 2014).

Dessa maneira, tem-se a importância de um estudo para identificação de micro-organismos, em conjunto com a CCIH, uma vez que essa identificação ajudará a desenvolver um conjunto de ações as quais podem reduzir a prevalência, incidência e gravidade da contaminação no ambiente hospitalar. Desse modo, o objetivo da pesquisa foi realizar uma análise microbiológica dos aparelhos celulares da equipe de enfermagem do setor da UTI de um hospital público no noroeste paranaense para determinar o índice de contaminação da UTI de acordo com os micro-organismos encontrados e como consequência, auxiliar principalmente a CCIH em medidas de prevenção. 


\section{Materiais e Métodos}

Foi realizado um estudo descritivo e qualitativo para determinar a prevalência de micro-organismos presentes em aparelhos celulares de colaboradores do setor da unidade de tratamento intensivo (UTI) de um hospital público do município de Maringá-PR. A participação dos colaboradores foi de forma voluntária e ocorreu mediante a assinatura do Termo de Consentimento Livre Esclarecido (TCLE).

O presente projeto foi aprovado tanto pela Assessoria de Formação e Capacitação Permanente dos Trabalhadores de Saúde (CECAPS) da Secretaria de Saúde da Prefeitura de Maringá sob o ofício no 3248/2018-SAÚDE quanto pelo Comitê de Ética em Pesquisa do Centro Universitário de Maringá (CEP-UniCesumar) sob o parecer $n^{0} 3.227 .942 / 2019$.

Os colaboradores que aceitaram participar da pesquisa responderam a um questionário com perguntas a respeito da manipulação do telefone celular e em seguida foram coletadas as amostras dos aparelhos com o auxílio de swabs estéreis umedecidos em caldo Brain Heart Infusion (BHI) que foram friccionados por toda a extensão dos aparelhos (tela, traseira e/ou parte posterior da capa de proteção). Imediatamente após a coleta, as amostras identificadas e inoculadas em tubos contendo caldo BHI foram transportadas em caixa de transporte de material biológico com gelo reutilizável e incubadas $\mathrm{a} \pm 35,5^{\circ} \mathrm{C}$ por 24 horas em estufa microbiológica do laboratório de microbiologia do Centro Universitário de Maringá (UniCesumar)

Todas as amostras após a incubação foram coradas pelo método de Gram (BRASIL, 2001) e semeadas de acordo com a técnica de semeadura de isolamento, utilizando-se alça bacteriológica de platina de $10 \mu \mathrm{L}$ em placas de Petri contendo meios seletivos como Ágar Sal Manitol e Ágar MacConkey, além de Ágar Sangue para identificação do grau de hemólise das bactérias, também foi realizada a análise de coliformes totais e termotolerantes através de tubos contendo caldo Lauril Sulfato de Sódio com tubo de Durhan invertido. As amostras foram novamente incubadas a $\pm 35,5^{\circ} \mathrm{C}$ por 24 horas.

Nos meios em que houve crescimento microbiológico, foram realizadas as provas bioquímicas da catalase e coagulase para diferenciação entre os gêneros Staphylococcus e Streptococcus (bactérias crescidas em Ágar Sal Manitol), além das provas do kit de enterobactérias e BacTray I, II e III (bactérias que cresceram em Ágar MacConkey).

Os dados dos resultados obtidos foram tabulados e analisados no editor de planilhas Microsoft Office Excel 2019.

\section{Resultados e Discussão}

O estudo foi realizado com a participação de 22 colaboradores do setor da UTI de um hospital público do noroeste paranaense, de ambos os sexos, com idade média de $40 \pm 8,9$ anos, variando entre 29 a 64 anos. Quanto à formação, em sua maioria, era composta por técnicos de enfermagem. Na tabela 1 são apresentados os dados demográficos dos entrevistados.
Tabela 1: Distribuição do perfil dos colaboradores participantes deste estudo, segundo características demográficas.

\begin{tabular}{lcc}
\hline \multirow{2}{*}{ Variável } & \multicolumn{2}{c}{ Frequência } \\
\cline { 2 - 3 } Total & $\mathbf{n}$ & \% \\
\hline Sexo & 22 & 100,0 \\
\hline Masculino & 5 & \\
Feminino & 17 & 22,7 \\
\hline Faixa etária & & 77,3 \\
\hline 29-34 & 8 & 36,4 \\
35-40 & 5 & 22,7 \\
41-46 & 5 & 22,7 \\
$\geq 47$ & 4 & 18,2 \\
\hline Formação & & \\
\hline Técnico de Enfermagem & 18 & 81,8 \\
Enfermeiro & 4 & 18,2 \\
\hline Período de trabalho & & 22,7 \\
\hline Manhã (07:00 as 13:00) & 5 & 13,6 \\
Tarde (13:00 as 19:00) & 3 & 63,6 \\
Noite (19:00 as 07:00) & 14 & \\
\hline & & \\
\hline
\end{tabular}

Foi coletada uma amostra do aparelho celular de cada um dos participantes e todas apresentaram crescimento de ao menos uma bactéria. A partir da análise da coloração de Gram, observou-se que todas as amostras apresentavam bactérias cocos gram-positivas na forma de cachos de uva, característico de estafilococos, e em 27,3\% $(n=6)$ das amostras visualizaram-se bactérias gram-negativas.

Para confirmação e identificação das amostras de estafilococos foi usada a prova da catalase e coagulase a partir do crescimento de amostras no meio seletivo ágar Sal Manitol, destacando-se que $72,7 \%(n=16)$ das amostras eram coagulase negativa, ou seja, Staphylococcus spp., e 27,3\% $(n=6)$ eram coagulase positiva e acidificaram o meio seletivo, identificando-se como Staphylococcus aureus.

A figura 1 mostra uma amostra com catalase positiva em ágar Sal Manitol (MAN) e ágar Sangue (AS), sendo positiva quando ocorre reação entre peróxido de hidrogênio com água + oxigênio da amostra, diferenciando o gênero estafilococos de estreptococos, nesse caso tratase de estafilococos. A figura 2 mostra uma amostra com coagulase positiva (formação de coágulo), característico de Staphylococcus aureus, e acidificação do meio seletivo ágar Sal Manitol, mudando a coloração para amarelo-dourado.

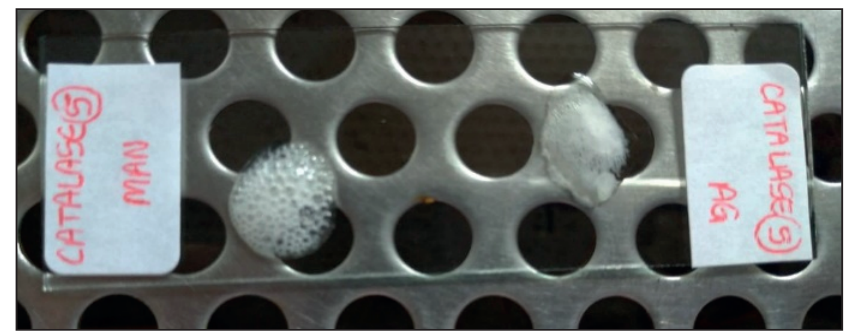

Figura 1: Amostra com catalase positiva, ocorrendo formação de bolhas. 


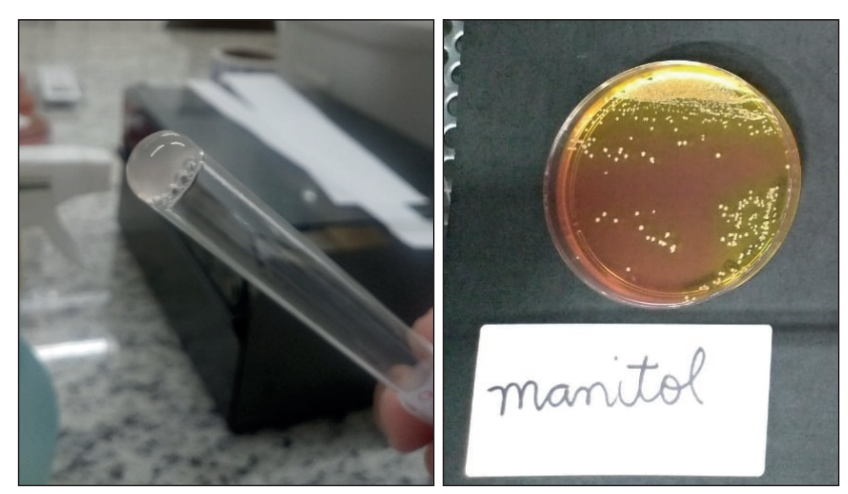

Figura 2: Amostra com coagulase positiva e acidificação do meio seletivo ágar Sal Manitol, características da família Staphylococcus aureus.

Nunes e Siliano (2016) identificaram bactérias do gênero estafilococos em $91 \%$ de suas amostras coletadas em aparelhos celulares de funcionários de um hospital e em estudos parecido de Araújo et al. (2017) e de Teixeira e Silva (2017) mostram que a maior prevalência encontrada é também do gênero estafilococos. Estes dados se assemelham com a nossa pesquisa principalmente por bactérias desse gênero serem encontradas na microbiota normal de seres humanos.

Existem mais de 40 espécies de Staphylococcus Coagulase-Negativos (SCN), sendo geralmente comensais não patogênicos de humanos e de outros animais, contudo não recebem tanta atenção na literatura quanto o Staphylococcus aureus, considerado mais virulento (PAHARIK et al., 2017). Por serem micro-organismos que habitam a pele, os SCN são considerados importantes patógenos em casos de lesão da barreira cutânea, causando graves infecções, principalmente em pacientes imunocomprometidos, prematuros e àqueles com implantes (LIMA et al., 2015).

A família Staphylococcus aureus se tornou uma das bactérias mais importantes de interesse clínico, sendo responsável por infecções hospitalares, comunitárias e intoxicações, dependendo da imunidade dos acometidos, a qual pode estar relacionada com doenças, feridas abertas ou medicamentos que afetam a imunidade do hospedeiro. Um dos motivos que permitem que esse micro-organismo seja patogênico é a existência de fatores de virulência que aproveitam da falha do sistema imune do hospedeiro, sendo que este coloniza facilmente a mucosa das narinas do homem (ARAÚJO et al., 2017).

Em 1970 começaram a aparecer cepas de Staphylococcus aureus com resistência à meticilina (MRSA), além de serem resistentes a outros antibióticos. As bactérias MRSA rapidamente conseguem se disseminar em ambiente hospitalares e acometem principalmente pacientes imunodeficientes e imunocomprometidos (GELATTI et al., 2009). No estudo de Reis e colaboradores (2015), foi identificado que $18 \%$ das amostras de aparelhos celulares dos funcionários que circulavam na UTI apresentavam MRSA, se tornando um veículo de transmissão para outras pessoas. Além disso, esse autor relata que bactérias conhecidas como MRSA podem resistir a semanas na superfície de diversos ambientes, incluindo locais estéreis. Em nossa pesquisa não realizamos a identificação se as cepas eram resistentes à meticilina e com isso não podemos afirmar e nem descartar a possibilidade de que os aparelhos poderiam estar contaminados com esse tipo de cepa.

As amostras gram-negativas foram semeadas em ágar MacConkey e, posteriormente, realizou-se as provas bioquímicas para identificação, sendo encontrados os gêneros Shigella $(4,5 \% ; n=1)$, Yersinia $(4,5 \% ; n=1)$, Serratia $(4,5 \% ; n=1)$, Salmonela $(4,5 \% ; n=1)$, Cedecea $(4,5 \% ; n=1)$ e Pseudomonas $(4,5 \% ; \mathrm{n}=1)$. A figura 3 mostra os dois kits utilizados na identificação desses micro-organismos, sendo um teste colorimétrico, que dependendo da coloração corresponde a uma série de números e a partir de uma tabela identificamos o micro-organismo. As bactérias encontradas em ágar MacConkey compreendem muitos dos patógenos isolados no homem e outros animais, sendo as principais causas de infecções intestinais (TEIXEIRA; SILVA, 2017).
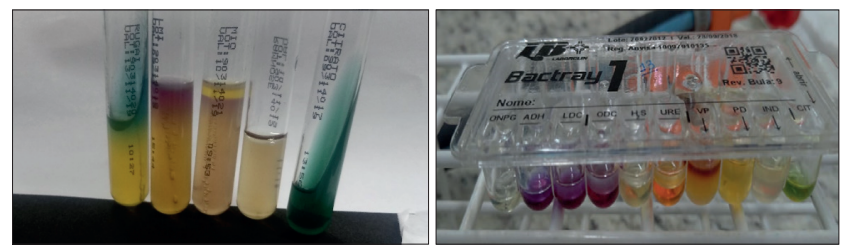

Figura 3: Provas bioquímicas realizadas com bactérias crescidas em ágar MacConkey, sendo da esquerda o kit de enterobactérias e o da direita o kit BacTray 1.

Todas as bactérias dogênero Shigella sãopatogênicos, infectando principalmente o homem e apresentam capacidade de invadir o epitélio da mucosa do intestino grosso, levando a quadros de inflamações, assim como também os gêneros Salmonella e Yersinia são encontrados em fezes humanas, água ou alimentos contaminados e a forma de transmissão ocorre por ingestão dessas bactérias. Para o gênero Cedecea não existem estudos aprofundados de transmissão dessa doença, sendo raramente encontradas, estando presentes em sangue e salivas, feridas e abscessos e em tecidos ulcerados (TEIXEIRA; SILVA, 2017).

O gênero Serratia é frequentemente adquirido em hospitais e ocorre principalmente em pacientes com imunidade diminuída. Em hospitais essa bactéria tende a colonizar o trato respiratório e urinário ao invés do gastrointestinal, em adultos, ocorrendo transmissão principalmente por contato direto das membranas mucosas com agentes infecciosos (AGUIAR e COMINALI, 2016). Por fim, o gênero Pseudomonas frequentemente causa infecções nos serviços de cuidados intensivos, geriátricos e infecções neonatais, sendo a sua transmissão em ambiente hospitalar, através de secreções do paciente infectados quando não são seguidas as normas básicas de desinfecção e higiene (MARTINS; KOZUSNY-ANDREANI; MENDES, 2018).

De acordo com o estudo não se esperava encontrar vários micro-organismos crescidos em ágar MacConkey por serem relatados como os principais causadores de IRAS nas UTIs. No estudo de Araújo e colaboradores (2017) foram encontradas bactérias gram-negativas como Enterobacter sp., Klebsiella sp. e Pseudomonas sp e no trabalho de Soares (2014) foram observadas Enterobacter spp., Citrobacter spp., Yersinia spp., Shigella spp. e Pseudomonas spp.

Para avaliarmos a higienização dos aparelhos celulares e quais cuidados os colaboradores tomam com 
seu objeto pessoal, foi aplicado um questionário contendo cinco perguntas, sendo possível correlacionar com os microorganismos encontrados nos aparelhos celulares desses colaboradores. A partir da tabela 2, verificou-se que muitos desses utilizam o aparelho celular no ambiente hospitalar, tornando-se um risco tanto ao paciente quanto as pessoas que circulam frequentemente naquele setor, tanto colaboradores quando visitantes, trazendo doenças de fora para dentro do ambiente hospitalar ou vice-versa. Além disso, as bactérias gram-negativas encontradas na pesquisa podem estar relacionadas com a frequência que os aparelhos celulares são levados ao banheiro quando os colaboradores o utilizam e também no leito do paciente.

Tabela 2: Porcentagem das perguntas respondidas do questionário pelos colaboradores.

\begin{tabular}{|c|c|c|c|c|c|c|}
\hline Pergunta & Nunca & $\begin{array}{l}\text { Muito } \\
\text { Pouco }\end{array}$ & Pouco & $\begin{array}{c}\text { Mais } \\
\text { ou } \\
\text { menos }\end{array}$ & Bastante & Sempre \\
\hline $\begin{array}{l}\text { Com que frequência utiliza o celular no ambiente } \\
\text { hospitalar? }\end{array}$ & - & $9,1 \%$ & $22,7 \%$ & $36,4 \%$ & $13,6 \%$ & $18,2 \%$ \\
\hline $\begin{array}{l}\text { Com que frequência utiliza o celular fora do ambiente } \\
\text { hospitalar? }\end{array}$ & - & - & - & $13,6 \%$ & $36,4 \%$ & $50,0 \%$ \\
\hline $\begin{array}{l}\text { Com que frequência leva o celular junto quando utiliza o } \\
\text { banheiro? }\end{array}$ & $22,7 \%$ & $45,5 \%$ & $4,5 \%$ & $4,5 \%$ & $4,5 \%$ & $18,2 \%$ \\
\hline Com que frequência leva o celular ao leito do paciente? & $81,8 \%$ & $9,1 \%$ & - & - & - & $9,1 \%$ \\
\hline Com que frequência faz higienização do celular? & $18,2 \%$ & $22,7 \%$ & $13,6 \%$ & $22,7 \%$ & $9,1 \%$ & $13,6 \%$ \\
\hline
\end{tabular}

No estudo realizado por Reis et al. (2015), foi aplicado um questionário para 50 indivíduos com objetivo de saber sobre a higienização dos aparelhos celulares no ambiente hospitalar, no qual foi observado que 38 dos entrevistados não realizavam a devida higienização em seu aparelho celular e com isso foi identificado um alto nível de contaminação nesse objeto.

Os principais fatores que influenciam em uma limpeza insatisfatória incluem baixa eficiência do biocida usado para desinfecção, micro-organismos bem adaptados à limpeza diariamente realizada, desinfetantes e banheiros contaminados e a errônea limpeza e higienização das mãos; sendo assim, esse tipo de análise poderá projetar melhores estratégias para procedimentos de limpeza. A identificação de gêneros relacionados a IRAS que estão concentrados em um hospital pode influenciar o uso futuro de protocolos e ferramentas aprimoradas para controle de infecção. (RIBEIRO et al., 2019).

Torna-se importante adquirir medidas para o controle de infecções hospitalares, especialmente no que se diz respeito ao uso de aparelhos celulares dentro de UTI. Esses profissionais devem ser orientados com medidas preventivas com relação à disseminação microbiológica por meio do uso dos aparelhos celulares dentro do ambiente hospitalar. Acreditamos que dessa maneira, será possível evitar estadias prolongadas de pacientes em leito e reduzir gastos com tratamento, além de transmitir para fora do hospital algumas bactérias encontradas nesses locais.

\section{Conclusão}

Os resultados obtidos na pesquisa mostraram contaminação em todos os aparelhos celulares, sendo encontradas em todas as amostras bactérias do gênero estafilococos, incluindo Staphylococcus aureus, que pode ser resistente à meticilina (MRSA) e causar graves problemas de saúde principalmente aos imunocomprometidos.

Além de bactérias cocos gram-positivas, foram encontradas bactérias gram-negativas e que podem estar relacionadas a uma higienização incorreta tanto dos aparelhos celulares quanto das mãos dos colaboradores, se tornando um risco tanto para os pacientes quanto para os próprios colaboradores no hospital.

O presente trabalho obteve resultados significativos sobre a prevalência de micro-organismos nos aparelhos celulares de colaboradores da UTI que contribuirão para promover a redução de infecções relacionadas à assistência à saúde. $\mathrm{O}$ desenvolvimento de medidas para vigilância microbiana a fim de se melhorar o controle de infecções é de extrema urgência; dessa forma espera-se o envolvimento da Comissão de Controle de Infecção Hospitalar (CCIH) para desenvolver ações que reduzam tanto a prevalência quanto a incidência da contaminação no ambiente hospitalar.

\section{Referências}

ABEGG, P. T. G. M.; SILVA, L. L. Controle de infecção hospitalar em unidade de terapia intensiva: estudo retrospectivo. Semina: Ciências Biológicas e da Saúde, v. 32, n. 1, p. 47-58, 2011.

AGUIAR, C. V.; COMINALI, E. L. B. Superfícies inanimadas como possíveis fontes de contaminações microbiológicas. Centro Universitário Toledo, São Paulo, 2016. Disponível em: http://www.unitoledo.br/repositorio/ handle/7574/144. Acesso em: 25 maio 2019.

ARAÚJO, A. M. et al. Ocorrência de microrganismos em aparelhos celulares no município de Ji-Paraná - Rondônia, Brasil. Brazilian Journal of Surgery and Clinical

Research - BJSCR, v. 19, n. 1, p. 10-15, 2017.

BALDO, A. et al. Contaminação microbiana de telefones celulares da comunidade acadêmica de instituição de ensino superior de Araguari (MG). Revista Master, v. 1, n. 1, p. 57-65, 2016. 
BARROS, M. M. et al. O enfermeiro na prevenção e controle de infecções relacionadas à assistência à saúde. Universitas: Ciências da Saúde, v. 14, n. 1, p. 15-21, 2016.

BRASIL. Ministério da Saúde. Portaria n 2616/MS/GM, de 12 de maio de 1998. Diário Oficial da República Federativa do Brasil, Brasília, DF, 1998. Disponível em: http://bvsms.saude.gov.br/bvs/saudelegis/gm/1998/ prt2616_12_05_1998.html. Acesso em: 25 maio 2019.

BRASIL. Ministério da Saúde. Secretaria de Políticas de Saúde. Técnica de Coloração de Gram. Brasília, DF, 2001. Disponível em: http://bvsms.saude.gov.br/bvs/ publicacoes/115_03gram.pdf. Acesso em: 27 fev. 2019.

BRASIL. Governo do Estado de São Paulo. Secretaria de Estado da Saúde. Divisão de Infecção Hospitalar. Melhore práticas para higiene e limpeza em ambiente hospitalar, p. 102, 2019. Disponível em: http://www.saude.sp.gov. br/resources/cve-centro-de-vigilancia-epidemiologica/ areas-de-vigilancia/infeccao-hospitalar/2019/ih19_manual_ higiene.pdf. Acesso em: 29 jan. 2019.

CHAVASCO, J. K. et al. Minicurso: Microbiologia e a microbiota humana. Universidade Federal de Alfenas (Unifal-MG), 2017. Disponível em: https://www.unifal-mg. edu.br/pet/sites/default/files/Apostila\%20Minicurso $\% 20$ Microbiol\%20Microb\%20Hum-PET-Biologia-Unifal.pdf. Acesso em: 29 mar. 2019.

CUSTÓDIO, J. et al. Avaliação microbiológica das mãos de profissionais da saúde de um hospital particular de Itumbiara, Goiás. Revista Ciências Médicas, v. 18, n. 1, p. 7-11, 2009.

LIMA, M. F. P. et al. Staphylococcus aureus e as infecções hospitalares - revisão de literatura. Revista UNINGÁ Review, v. 21, n. 1, p. 32-39, 2015.

MARTINS, C. C.; KOZUSNY-ANDREANI, D. I.; MENDES, E. C. B. Isolamento e identificação de microorganismos patogênicos em resíduos sólidos de serviços de saúde. Revista Funec Científica - Enfermagem, v. 2, n. 3, p. 29-37, 2018.

NUNES, K. O.; SILIANO, P. R. Identificação de bactérias presentes em aparelhos celulares. Science in Health, v. 7, n. 1, p. 22-25, 2016.

PAHARIK, A. E. Coagulase-Negative Staphylococcal strain prevents Staphylococcus aureus colonization and skin infection by blocking quorum sensing. Cell Host \& Microbe, v. 22, n. 6, p. 746-756, 2017.

RAPPAPORT, T. S. Comunicações Sem Fio - Princípios e Práticas. 2. ed. São Paulo: Prentice Hall Brasil, 2009.

REIS, L. E. et al. Contaminação de telefones celulares da equipe multiprofissional em uma unidade de terapia intensiva. Revista Saber Digital, v. 8, n.1, p. 68-83, 2015.
RIBEIRO L. F. et al. Microbial Community Profiling in Intensive Care Units Expose Limitations in Current Sanitary Standards. Front. Public Health, 7:240, 2019.

SALOMÃO, R.; PIGNATARI, A. C. C. Guias de Medicina Ambulatorial e Hospitalar UNIFESP - Infectologia. 1. ed. São Paulo: Manole, 2004.

SOARES JUNIOR, R. S. Análise Bacteriana de Telefones Celulares de Profissionais da Saúde do Setor Hospitalar de Palmas, TO. 2014. 35 f. Trabalho de Conclusão de Curso (Faculdade de Biomedicina) - Centro Universitário Luterano de Palmas, Palmas - Tocantins, 2014.

STUCHI, R. A. G. et al. Bacterial and Fungal Contamination of Mobile Phones Belonging to the Health Team of a Hospital in Minas Gerais State. Revista Ciência, Cuidado e Saúde, v. 12, n. 4, p. 760-767, 2013.

TEIXEIRA, F. N.; SILVA, C. V. Análise microbiológica em telefones celulares. Revista F@pciência, v. 11, n. 3, p. 1524, 2017.

TUNKEL, A. R. Prevenção de infecção. Manual MSD - Versão Saúde para a Família, 2002. Disponível em: https://www.msdmanuals.com/pt-br/casa/ infec $\% \mathrm{C} 3 \% \mathrm{~A} 7 \% \mathrm{C} 3 \% \mathrm{~B} 5 \mathrm{es} /$ biologia-das-doen $\% \mathrm{C} 3 \% \mathrm{~A} 7 \mathrm{as}-$ infecciosas/preven $\% \mathrm{C} 3 \% \mathrm{~A} 7 \% \mathrm{C} 3 \% \mathrm{~A} 3 \mathrm{o}$-deinfec $\%$ C3\%A7\%C3\%A3o. Acesso em: 29 mar. 2019.

Recebido em: 25/05/2020 Aceito em: 14/03/2021 